Published: March 15, 2019

Corresponding Author:

John Okoye

Email: joaokoye@yahoo.com

Copyright:

(우 (1) (3)

(C) 2019 Science Publishing Group

This open access article is distributed under the terms of the Creative Commons Attribution NonCommercial License.
REVIEW ARTICLE

\section{La Sota Vaccination Does Not Offer Satisfactory Protection Against Velogenic Newcastle Disease Virus Infection In Chickens- A Review}

Authors

J O A Okoye and A O Igwe

\section{Author's affiliations:}

-Department of Veterinary Pathology and Microbiology, University of Nigeria, Nsukka, Enugu State, Nigeria

-Department of Veterinary Pathology, Michael Okpara University of Agriculture, Umudike, Abia State, Nigeria

\begin{abstract}
La Sota vaccination is the major vaccine used in the control of Newcastle disease (ND) of chickens in most countries of Europe and United States of America where millions of chickens are kept in one farm at a time. La Sota vaccine is administered through drinking water and can be easily administered on millions of chickens in few hours. Furthermore, the predominant field ND virus pathotype in these countries is the mesogenic virus for which La Sota vaccination is effective in providing protection. But this same vaccine has been found to be ineffective against velogenic ND virus pathotype which is enzootic in Africa, Middle and Far East. This makes large scale poultry production difficult in these areas. The Komarov ND vaccine which is effective against the velogenic ND virus is administered intramuscularly and requires individual handling of the chickens which is not possible where millions of chickens are housed together.
\end{abstract}




\section{DISCUSSION}

Newcastle disease (ND) is a major disease of poultry worldwide (Alexander and Senne, 2008). The virus infects a wide range of avian species including poultry, cage and wild birds (Kaleta and Baldauf, 1988). Chickens are most severely affected probably because it is only in this species that ND causes severe haemorrhagic and ulcerative lesions in the gastrointestinal tract (Okoroafor et al, 2018). The velogenic form of ND is the most severe form of the disease and usually causes mortalities of up to 70 to $100 \%$ within seven days in susceptible chickens (Igwe et al. 2018). Okpe et al (2015) reported that dietary supplementation of vitamin A significantly reduced the mortality of velogenic ND (VND) in chickens. VND is enzootic in Africa, Middle and Far East (Echeonwu et al, 1993; Solomon et al, 2012 and Shittu et al, 2016) and it is a major factor militating against poultry production in these areas (Czegledi et al, 2006). The outbreaks cause huge economic losses to poultry producers because of heavy mortalities, loss of egg production, imposition of trade embargo by the international community and the stamping out control policy used to control the disease in those countries where VND is exotic.

Control of ND is mainly by vaccination and biosecurity. Recently, researchers have discovered many inadequacies and problems in the control of VND with La Sota vaccination. Ezema et al (2009) challenged La Sota vaccinated and unvaccinated chickens with velogenic viscerotropic ND virus and reported that there was no clinical sign in the vaccinated chickens but the mortality in unvaccinated was $84.6 \%$. But the atrophy, necrosis and the depletion of the lymphocytes in the bursa, spleen and thymus were equally very severe in both vaccinated and unvaccinated. It was concluded that La Sota vaccination protected chickens against the clinical signs of VND but not against the lesions of the disease in the lymphoid organs. These observations and conclusion were later confirmed by Bwala et al (2012) and Ezema et al (2016) in chickens. Okoroafor et al (2018) confirmed this observation in vaccinated and unvaccinated turkeys. Eze (2017) reported that these lymphocidal lesions significantly $(p<0.05)$ reduced antibody responses to infectious bursal disease and infectious bronchitis disease vaccination in both La Sota vaccinated and unvaccinated chickens. It has also been observed by several researchers that La Sota vaccination does not stop the multiplication of the ND virus (NDV) but reduces the shedding of the virus through the faeces and eggs (Miller et al, 2007 \&2013; Bwala et al, 2012; Cattoli et al, 2013; Okwor et al, 2016; Sa e Silva et al, 2016 and Okoroafor et al, 2018) in chickens and turkeys. Igwe et al (2018a) challenged La Sota vaccinated and unvaccinated laying chickens with VND virus (VNDV). Severe clinical signs and mortality of $90 \%$ were observed in the unvaccinated but clinical signs were mild and there was no mortality in the vaccinated layers. There was significant $(p<0.05)$ drop in egg production in both vaccinated and unvaccinated layers throughout the seven weeks duration of the experiment, even though the drop was more severe in the unvaccinated. This confirms the earlier reports of Bwala et al (2012) and Sa e Silva et al (2016) who also reported drop in egg production in both challenged La Sota vaccinated and unvaccinated laying chickens. This can constitute huge economic loss to egg producers. Only the 
unvaccinated layers produced discoloured (white), thin shelled and misshaped eggs. Pathological changes in the gastrointestinal tract, female reproductive organs and immunohistochemical labeling were more severe in the unvaccinated than the vaccinated layers. Igwe et al (2018b) observed that the drop in egg production in VNDV infected laying chickens was strongly and positively correlated with drop in serum phosphorous levels. The above observations show that La Sota vaccination:

i. Does not protect chickens against the lesions of VND in the lymphoid organs. Immunosuppression is the consequence

ii. Does not protect chickens against VNDV shedding. Environmental pollution is the consequence

iii. Does not protect laying chickens against drop in egg production due to VND. Huge economic loss is the consequence.

These conditions are not compatible with profitable poultry farming. In developed countries of Europe and America where poultry production has metamorphosed into large industries where millions of chickens are reared in one farm at the same time, La Sota vaccination at specific intervals is now the practice. Komarov vaccination which is administered at the breast muscle of the chickens at six weeks of age is ruled out because it is impossible to handle millions of chickens individually. Komarov is a mesogenic NDV and will produce stronger protection than La Sota which is a lentogenic NDV. The current practice in developed countries may not expose the chickens to much risk because VND is exotic in those countries and their biosecurity practice is very strong. But it will be risky to embark on large scale poultry production with only La Sota vaccination in those areas where VND is enzootic. Generally, biosecurity practice is weak in Africa. The solution may be to have another look at the La Sota vaccine and the vaccination schedule to make them effective for the control of VND. 


\section{References}

1. Alexander, D.J. and Senne, D.A., 2008. ND and other avian parasmyxovirus infections. In: Diseases of Poultry $12^{\text {th }}$ edition, Y.M. Saif, H.J. Barnes, J.R. Glisson, A.M. Fadly, L.R. McDougal, D.E. Swayne (Eds). lowa state University Press, Ames, IA. P. 75-100.

2. Bwala, D. G., Clift, S., Duncan, N M., Bisschop, S P R.and Oludayo, Fasina F 2012. Determination of the distribution of lentogenic vaccine and virulent Newcastle disease virus angtien in the oviduct of SPF and commercial hen using immunohistochemistry. Research in Veterinary. Science, 93, $520-528$.

3. Cattoli, G, Susta, L, Terregino, C, and Brown, C 2011. Newcastle disease: a review of field recognition and current methods of laboratory detection. Journal of Veterinary Diagnostic Investigation, 23, 637-656

4. Czegledi, A., Ujvari, D., Somogyi, E., Wehmann E., Werner, O.and Lomniczi, B., 2006. Third genome size category of avian paramyxovirus serotype 1 (Newcastle disease virus) and evolutionary implications. Virus Research, 120, 36-48

5. Echeonwu, G. O. N., Ireogbu, C. I. and Emeruwa, A. C., 1993. Recovery of velogenic Newcastle disease virus from dead and healthy free roaming birds in Nigeria. Avian Pathology, 22, 383-38

6. Eze, D C (2017). Evaluation of humoral immunosuppressive properties velogenic viscerotropic Newcastle disease virus infection in chickens. PhD Thesis. Department of Veterinary Pathology and Microbiology, University of Nigeria, Nsukka, Nigeria

7. Ezema, W.S., Okoye, J O A and Nwanta, J A. 2009. Lasota vaccination may not protect against the lesions of velogenic Newcastle disease in chickens. Tropical Animal Health and Production, 41, $477-484$.

8. Ezema, W. S., Eze, D. C., Shoyinka, S.V.O. and Okoye, J. O. A. 2016. Atrophy of the lymphoid organs and suppression of antibody response caused by velogenic Newcastle disease virus infection in chickens. Tropical Animal Health and Production, 48, 1703-1709.

9. Igwe, A O., Afonso, C L., Ezema, W S ., Brown, C C and Okoye, J O A. 2018a. Pathology and distribution of velogenic viscerotropic Newcastle disease virus in the reproductive system of vaccinated and unvaccinated laying hens (Gallus gallus domesticus) by immunohistochemical labelling. Journal of Comparative Pathology, 159, 36-48. Doi.org/10.1016/i.jcpa.2017.12.009

10. Igwe, A O, Ihedioha, J I and Okoye, J O A. 2018b. Changes in serum calcium and phosphorus levels and their relationship with egg production in laying chickens infected with velogenic Newcastle disease virus. Journal of Applied Animal Research, 46, 523-528, doi.org/10.1080/09712119.2017.1352506

11. Kaleta, E F and Baldauf, C.1988. Newcastle disease in free-living and pet birds. In: Alexander, D J (Ed). Newcastle Disease. Kluwer Academic Publishers, Boston, pp 197-246 
12. Miller, P. J., King, D. J., Afonso, C.L and Suarez, D. L. 2007. Antigenic differences among Newcastle disease virus strains of different genotypes used in vaccine formulation affect viral shedding after a virulent challenge. Vaccine, 25, 7238-7246.

13. Miller, P. J., Afonso, C. L., Attrache, J. E., Dorsey, K.M., Courtney, S.C., Guo, Z and Kapczynski, D. R. 2013. Effects of Newcastle disease VCrus vaccine antibodies on the shedding and transmission of challenge viruses. Developmental and Comparative Immunology, 41, 505-513.

14. Okoroafor, O A, Eze, P C, Ezema, W S, Nwosu, C, Okorie-Kanu, C, Animoke, P C, Anene, B and Okoye, J O A. 2018. La Sota vaccination may not protect against virus shedding and lesions of velogenic Newcastle disease in commercial turkeys. Tropical Animal Health and Production, 50,345-351. DOI.org/10.1007//s 1125-017-1439-9.

15. Okpe, G C, Ezema, W S, Shoyinka, S V O and Okoye, J O A. 2015. Vitamin A dietary supplementation reduced the mortality of velogenic Newcastle disease significantly in cockerels. International Journal of Experimental Pathology, 96, 326-331. Ol:10.1111/iep.12138

16. Okwor, E C, Eze, D C, Echeonwu, G O N, Ibu, J O, Eze, P C and Okoye, J O A. (2016).Comparative studies on the effects of La Sota and Komarov vaccine antibodies on organ distribution, persistence and shedding of KUDU 113 virus in chickens. The Journal of Animal \& Plant Sciences, 26,1226-123

17. Sa e Silva, M. S., Susta, L., Moresco, K.and Swayne, D. E. 2016. Vaccination of chickens decreased Newcastle disease virus contamination in eggs. Avian Pathology, 45, 38- 45

18. Shittu, I, Sharma P., Joannis, T. M., Volkening, J. D., Odaibo, G. N., Olaleye, D. O., Williams-Coplin, D., Solomon, P., Abolnik, C., Miller, P. J., Dimitrov, K. M and Afonso, C. L. 2016. Complete genome sequence of a genotype XVII Newcastle disease virus, isolated from an apparently healthy domestic duck in Nigeria. Genome Announcement, 4, e01716-15. doi:10.1128/ genomeA.01716-15 .

19. Solomon, P., Aboinik, C., Joannis, T M and Bisschop S. 2012. Virulent Newcastle disease virus in Nigeria: identification of a new clade of sub-lineage $5 \mathrm{f}$ from live bird markets. Virus Genes, 44, 98-103 